Journal of Computer Science 8 (9): 1482-1486, 2012

ISSN 1549-3636

(C) 2012 Science Publications

\title{
An Effective Biogeography Based Optimization Algorithm to Slove Economic Load Dispatch Problem
}

\author{
${ }^{1}$ Vanitha, M. and ${ }^{2} \mathrm{~K}$. Thanushkodi \\ ${ }^{1}$ Department of Electrical and Electronics Engineering, \\ Coimbatore Institute of Engineering and Technology, Coimbatore, India \\ ${ }^{2}$ Department of Electrical and Electronics Engineering, \\ Akshaya College of Engineering and Technology, Kinathukadavu, Coimbatore, India
}

\begin{abstract}
Problem statement: Implementation of an Effective Biogeography Based Algorithm (EBBO) for Economic Load Dispatch (ELD) problems in power system in order to obtain optimal economic dispatch with minimum generation cost. Approach: A viable methodology has been implemented for a 20 unit generator system to minimize the fuel cost function considering the transmission loss and system operating limit constraints and is compared with other approaches such as BBO, Lambda Iteration and Hopfield Model. Results: Proposed algorithm has been applied to ELD problems for verifying its feasibility and the comparison of results are tabulated and pictorial visualization for convergence of EBBO is represented. Conclusion: Comparing with the other existing techniques, the EBBO gives better result by considering the quality of the solution obtained. This method could be an alternative approach for solving the ELD problems in practical power system.
\end{abstract}

Key words: Economic Load Dispatch (ELD), Effective Biogeography Based Algorithm (EBBO), low generation cost, quadratic cost function, lambda iteration, hopfield model

\section{INTRODUCTION}

The most significant crisis in the planning and operation of electric power generation system is the effective scheduling of all generators in a system to meet the required demand. The Economic Load Dispatch (ELD) is the important optimization problem to schedule the generation among generating units in power system. The main aim of ELD problem is to minimize the operation cost by satisfying the various operational constraints in order met the load demand. Many traditional algorithms (Wood and Wollenberg, 1996) like lambda iteration, Gradient search, Newton method are applied to optimize ELD problems however in these methods it is assumed that the incremental cost curves of the units are monotonically increasing piecewise linear functions, but the practical systems are nonlinear.

In the past years many optimization algorithms are being developed to solve the ELD problems such as Genetic Algorithms (GA) (Chen and Chang, 1995; Orero and Irving, 1996) Particle Swarm Optimization (PSO) (Gaing, 2003; Selvakumar and Thanushkodi, 2007; Kuo, 2008; Khamsawang et al., 2009), Simulated Annealing (SA) (Wong and Fung, 1993; Wong, 1995), Differential Evolution (DE) (Das et al., 2008; Khamsawang and Jiriwibhakorn, 2009) and Corresponding Author: Vanitha, M., Department of Electrical and Electronics Engineering, Coimbatore Institute of Engineering and Technology, Coimbatore, India
Biogeography Based Optimization (BBO) (Bhattacharya and Chattopadhyay, 2010a). GA is inspired by the study of genetics and conceptually based on natural evolution mechanisms. PSO is a robust stochastic optimization technique based on the movement and intelligence of swarms. SA is a stochastic optimization technique which is based on the principles of statistical engineering. DE is technically population based Evolutionary Algorithm. Biogeography is the nature's way of distributing species. The migration of species from one island to another, evolution of new species and extinction of species are expressed by the mathematical models of biogeography. This study describes a new optimization algorithm, an Effective Biogeography Based Optimization Algorithm. This algorithm is validated by applying it to 20 units system with generator constraints, power balance constraints and transmission loss. The total generation cost and the computational time obtained by this method is better or comparable when compared to other methods.

\section{MATERIALS AND METHODS}

The ELD problem having an objective function minimizes the total generation cost, $\mathrm{F}_{\mathrm{T}}$, while fulfilling 


\section{J. Computer Sci., 8 (9): 1482-1486, 2012}

various constraints when supplying the required load demand of a power system. The objective function is given by Eq. 1:

$$
\min \mathrm{F}_{\mathrm{T}}=\min \left(\sum_{\mathrm{i}=1}^{\mathrm{n}} \mathrm{F}_{\mathrm{i}}\left(\mathrm{P}_{\mathrm{Gi}}\right)\right)=\min \left(\sum_{\mathrm{i}=1}^{\mathrm{n}} \mathrm{A}_{\mathrm{i}} \mathrm{P}_{\mathrm{Gi}}^{2}+\mathrm{B}_{\mathrm{i}} \mathrm{P}_{\mathrm{Gi}}+\mathrm{C}_{\mathrm{i}}\right)
$$

where, $\mathrm{P}_{\mathrm{Gi}}$ is the output power generated by the ith generator, $\mathrm{F}_{\mathrm{i}}\left(\mathrm{P}_{\mathrm{Gi}}\right)$ is the Generation cost function of ith generator and $A_{i}, B_{i}, C_{i}$ are the Cost coefficients of ith generator, $\mathrm{n}$ is the number of generators.

Two constraints are considered in this problem, i.e., the generation capacity of each generator and the power balance of the entire power system.

Constraint 1: This constraint is an inequality constraint for each generator. For normal system operations, real power output of each generator is within its lower and upper bounds and is known as generation capacity constraint given by Eq. 2:

$\mathrm{P}_{\mathrm{Gi}}^{\min } \leq \mathrm{P}_{\mathrm{Gi}} \leq \mathrm{P}_{\mathrm{Gi}}^{\max }$

where, $\mathrm{P}_{\mathrm{Gi}}^{\min }$ and $\mathrm{P}_{\mathrm{Gi}}^{\max }$ are the lower and upper limit of the power generated by ith generator.

Constraint 2: This constraint is an equality constraint. In which the equilibrium is met when the total power generation must equals the total demand $\mathrm{P}_{\mathrm{D}}$ and the real power loss in transmission lines $\mathrm{P}_{\mathrm{L}}$. This is known as power balance constraint can be expressed as given in Eq. 3:

$$
\sum_{i=1}^{n} P_{G i}=P_{D}+P_{L}
$$

The transmission losses are considered as a function of the generators output, can be expressed as given in Eq. 4:

$$
\mathrm{P}_{\mathrm{L}}=\sum_{\mathrm{i}=1}^{\mathrm{n}} \sum_{\mathrm{j}=1}^{\mathrm{n}} \mathrm{P}_{\mathrm{Gi}} \mathrm{B}_{\mathrm{ij}} \mathrm{P}_{\mathrm{Gj}}+\sum_{\mathrm{i}=1}^{\mathrm{n}} \mathrm{B}_{\mathrm{oi}} \mathrm{P}_{\mathrm{Gi}}+\mathrm{B}_{\mathrm{oo}}
$$

where, $\mathrm{B}_{\mathrm{ij}}, \mathrm{B}_{\mathrm{oi}}, \mathrm{B}_{\mathrm{oo}}$ are the transmission power loss $\mathrm{B}$ coefficients, which are assumed to be constant. In the summary, the objective of economic power dispatch optimization is to minimize $\mathrm{F}_{\mathrm{T}}$ subject to the constraints given by the Eq. 2-4.

Particle Swarm Optimization: PSO is a population based optimization technique, motivated by biological concepts like swarming and flocking. PSO is initialized with the population, which is randomly generated and it always conducts a search in the population of particles. Every particle in the population represents a possible candidate solution (i.e. fitness) to the given problem. In a PSO system, the search towards optima is carried out in a multidimensional search space. Every particle memorizes its best solution in addition to its position achieved so far is known as Pbest, the Personal best. It also knows the best value along with its position found in the group among Pbest, known as Gbest, the Global best. The basic theory of PSO insists on accelerating each particle towards its Pbest and the Gbest locations as shown in Fig. 1.

Differential evolution: DE is also a population based optimization algorithm. The optimization process in DE is carried with four basic operations namely, Initialization, Mutation, Crossover and Selection. Through initialization operation new population is created and the individuals are known as target vectors. New parameters are introduced by the mutation operation into the population and generate a mutant vector. The crossover operation generates trial vectors by combining the parameter of the mutant vectors with the target vectors. Selection is the process through which the next generation population vector is created by comparing the fitness of target vector and trial vector.

Biogeography: $\mathrm{BBO}$ is based on the concept of Biogeography, two different processes identified as Migration and Mutation are carried out. The population of individuals or candidate solutions can be represented as a solution vector having integers. Every integer in the solution vector is equal to one SIV. The quality of the solutions is evaluated by SIVs. The good solutions are considered as high HSI habitats where as others are known as low HSI habitats. The habitats HSI is the fitness function to a given problem. By using the migration operation the information is shared between habitats probabilistically. A sudden change can occur in the HSI of a natural habitat due to some natural calamities or other events known as mutation. The diversity of the populations is increased by the mutation

Proposed EBBO approach: A popular research trend is to merge or combine the PSO with the other techniques, especially the other evolutionary computation techniques. Evolutionary operators like selection, crossover and mutation have been applied into the PSO. In EBBO approach, first the PSO concept is used to initialize the population of particle with its velocity and position. 


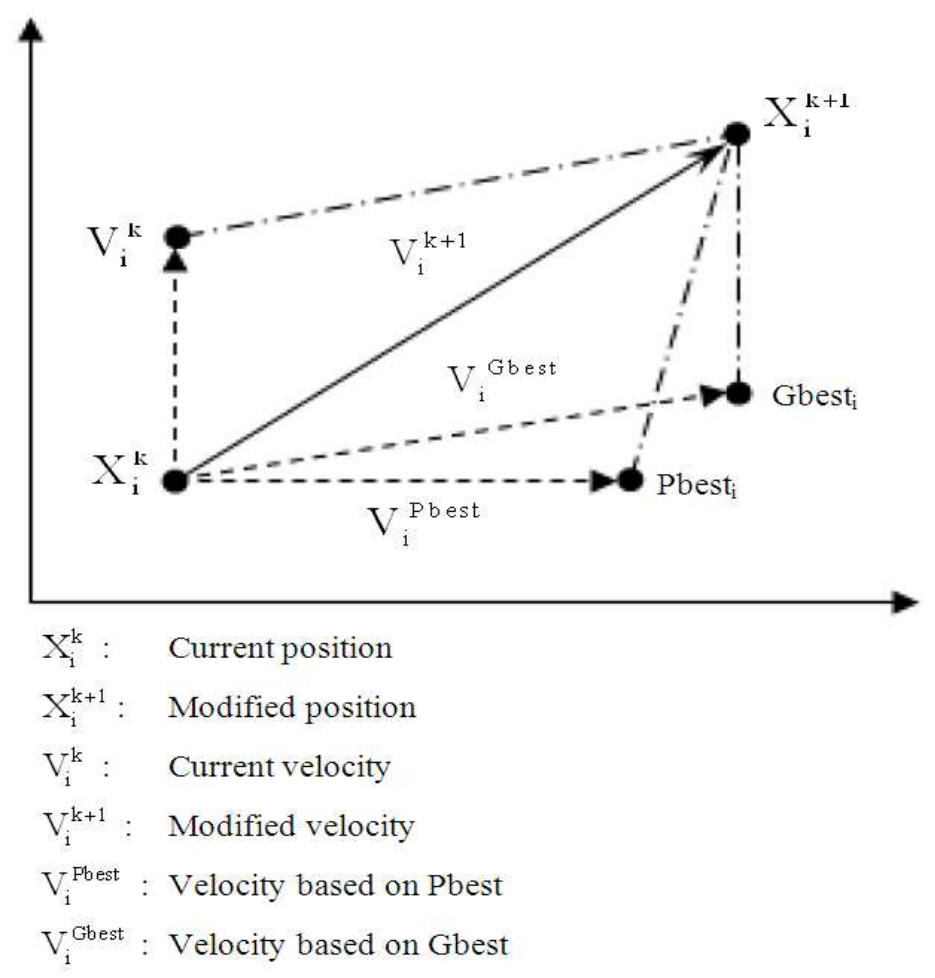

Fig. 1: Concept of modification of a searching point by PSO

The velocity of the particle is updated if the calculated velocity is out of boundary or closely to zero (rand $(0$, 1)), a mutation operator of the DE is activated; recalculate the velocity of this particle by using $\mathrm{DE}$ mutation operator. If the calculated velocity using DE is less than crossover rate (CR), calculate the immigration rate $\lambda$ and the emigration rate for each individual $\mathrm{Xi}$ and Modify the population with migration operator and update the position according to the new velocity. Using this, again calculate the Gbest value.

\section{EBBO Algorithm:}

Step 1: The individuals of the population are randomly initialized. The velocities of the different particles are also randomly generated keeping the velocity within the maximum and minimum value $[0.5$ to -0.5$]$. These initial individuals must be feasible candidate solutions that satisfy the practical operation constraints (both the linear and non-linear constraints) of the given problem. Choose CR, F values.

Step 2: The cost function of each individual is calculated in the population using the evaluation function $\mathrm{F}_{\mathrm{T}}$. The present value is set as the pbest value.
Step 3: Each pbest values are compared with the other pbest values in the population. The best evaluation value among the pbest is denoted as gbest.

Step 4: The member velocity $\mathrm{V}$ of each individual in the population is updated according to the velocity update Equation

$$
\begin{aligned}
\mathrm{V}_{\mathrm{i}}^{(\mathrm{t}+1)}= & \mathrm{w} \times \mathrm{V}_{\mathrm{i}}^{(\mathrm{t})}+\mathrm{c}_{1} \times \mathrm{r}_{1} \times\left(\text { pbest }_{\mathrm{i}}-\mathrm{x}_{\mathrm{i}}^{(\mathrm{t})}\right) \\
& +\mathrm{c}_{2} \times \mathrm{r}_{2} \times\left(\text { gbest }-\mathrm{x}_{\mathrm{i}}^{(\mathrm{t})}\right)
\end{aligned}
$$

Step 5: The member velocity, $\mathrm{V}$ of each individual in the population is checked. If the calculated velocity is out of boundary or closely to zero (rand $(0,1)$ ), a mutation operator of the DE is activated, recalculate the velocity of this particle by using mutation operator

$$
\mathrm{V}_{\mathrm{i}}^{(\mathrm{t}+1)}=\mathrm{F} \times\left(\left(\mathrm{x}_{\mathrm{k}}^{(\mathrm{t})}-\mathrm{x}_{\mathrm{i}}^{(\mathrm{t})}\right)-\left(\mathrm{x}_{\mathrm{q}}^{(\mathrm{t})}-\mathrm{x}_{\mathrm{i}}^{(\mathrm{t})}\right)\right)
$$

Else go to step 8, without activating DE mutation operator.

Step 6: If the calculated velocity using DE is less than $\mathrm{CR}$ value, Calculate the immigration rate $\lambda$ and the emigration rate for each individual $X i$ Else go to step 8 


\section{J. Computer Sci., 8 (9): 1482-1486, 2012}

Step 7: Modify the population with migration operator and go to step 2

Step 8: The position of each individual is modified according to the position update equation New position $=$ old position + updated velocity Go to step 2

Step 9: Continue the process, until a maximum iteration is obtained.

\section{RESULTS}

The performance of the proposed algorithm was tested on a 20-unit system with a demand of $2500 \mathrm{MW}$. The software was written in matlab-7 and executed.
The results of fuel cost and cpu time obtained by the proposed EBBO algorithm are compared with other methods such as BBO (Bhattacharya and Chattopadhyay, 2010b), Lambda Iteration and Hopfield Model (Su and Lin, 2000) to evaluate the performance of the proposed method.

The input data and transmission loss coefficients for 20 units system is taken from ( $\mathrm{Su}$ and Lin, 2000). Table 1 provides the statistic results that involved the generation cost, evaluation value and CPU time. Table 2 provides the parameter setting for the proposed method. Figure 2 provides the characteristics graph between iteration and the total generation cost.

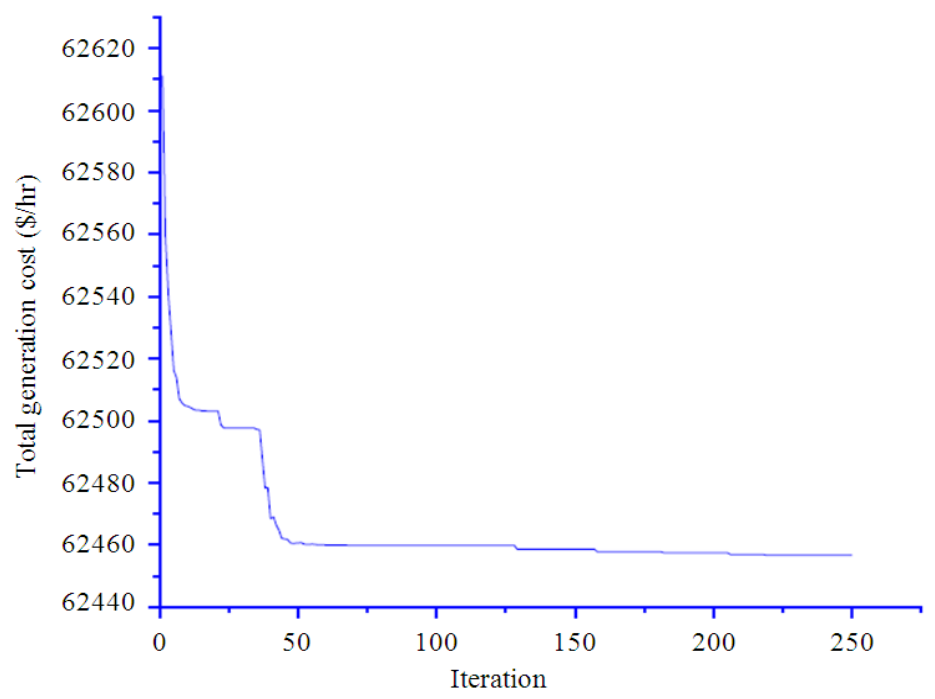

Fig. 2: Convergence characteristic of 20-generator system

Table 1: Best Power Output for 20-Generator System

\begin{tabular}{|c|c|c|c|c|}
\hline Unit output & EBBO & $\mathrm{BBO}$ & Lambda iteratio & Hopfield model \\
\hline P1 (MW) & 513.4359 & 513.08920 & 512.780500 & 512.780400 \\
\hline P2 (MW) & 169.6626 & 173.35330 & 169.103300 & 169.103500 \\
\hline P3 (MW) & 127.4739 & 126.92310 & 126.889800 & 126.889700 \\
\hline P4 (MW) & 103.1807 & 103.32920 & 102.865700 & 102.865600 \\
\hline P5 (MW) & 113.9900 & 113.77410 & 113.683600 & 113.683600 \\
\hline P6 (MW) & 73.5092 & 73.06694 & 73.571000 & 73.570900 \\
\hline P7 (MW) & 115.3057 & 114.98430 & 115.287800 & 115.287600 \\
\hline P8 (MW) & 116.6982 & 116.42380 & 116.399400 & 116.399400 \\
\hline P9 (MW) & 100.7520 & 100.69480 & 100.406200 & 100.406300 \\
\hline P10 (MW) & 106.2595 & 99.99979 & 106.026700 & 106.026700 \\
\hline P11 (MW) & 150.3157 & 148.97700 & 150.239400 & 150.239500 \\
\hline P12 (MW) & 291.6540 & 294.02070 & 292.764800 & 292.764700 \\
\hline P13 (MW) & 119.3330 & 119.57540 & 119.115400 & 119.115500 \\
\hline P14 (MW) & 30.9885 & 30.54786 & 30.834000 & 30.834200 \\
\hline P15 (MW) & 115.9033 & 116.45460 & 115.805700 & 115.805600 \\
\hline P16 (MW) & 36.2575 & 36.22787 & 36.254500 & 36.254500 \\
\hline P17 (MW) & 67.1866 & 66.85943 & 66.859000 & 66.859000 \\
\hline P18 (MW) & 88.0014 & 88.54701 & 87.972000 & 87.972000 \\
\hline P19 (MW) & 101.0420 & 100.98020 & 100.803300 & 100.803300 \\
\hline P20 (MW) & 51.0917 & 54.27250 & 54.305000 & 54.305000 \\
\hline Total Power Output (MW) & 2592.0410 & 2592.10100 & 2591.967000 & 2591.967000 \\
\hline Total Generation Cost $(\$ / \mathrm{h})$ & 62456.6300 & 62456.79000 & 62456.640000 & 62456.630000 \\
\hline Power Loss) (MW) & 91.5352 & 92.10110 & 91.967000 & 91.966900 \\
\hline CPU time/ iteration $(\mathrm{sec})$ & 0.0650 & 0.29282 & 0.033757 & 0.006355 \\
\hline
\end{tabular}


Table 2: Parameter Settings

\begin{tabular}{lllllllll}
\hline $\mathrm{C} 1$ & $\mathrm{C} 2$ & Iteration & $\omega_{\min }$ & $\omega_{\max }$ & $\mathrm{CR}$ & $\mathrm{F}$ & $\mu$ & $\lambda$ \\
\hline 2 & 2 & 250 & 0.9 & 0.9 & 0.89 & 0.8 & 0.9 & 1 \\
\hline
\end{tabular}

\section{DISCUSSION}

The previous method results taken from the literature is compared with the proposed method. The comparison proves that all the four algorithms have the potential to find the global solution, but the minimum generation costs achieved by EBBO is less than those reported in recent literature. It is also clear that the EBBO algorithm is efficient and require less computational time. As a whole it can be said that the EBBO algorithm is computationally efficient than earlier mentioned methods. Thus, the EBBO algorithm is more reliable to find out the minimum fuel cost in this example.

\section{CONCLUSION}

This study presents a novel coding scheme for EBBO algorithm to solve practical ELD issues and confirmed by a simulation process. The proposed combined method uses the mutation property of DE and migration property of $\mathrm{BBO}$ in $\mathrm{PSO}$, which can provide a good optimal solution even when the problem begins with optimal solution. The performance of proposed coding scheme used in the case study of 20-units system with transmission loss, proved to have salient features including better quality solution, stable convergence characteristics and good computational efficiency when compared with the results obtained from other heuristic methods.

\section{REFERENCES}

Bhattacharya, A. and P.K. Chattopadhyay, 2010a. Biogeography-based optimization for different economic load dispatch problems. IEEE Trans. Power Syst., 25: 1064-1077. DOI: 10.1109/TPWRS.2009.2034525

Bhattacharya, A. and P.K. Chattopadhyay, 2010b. Hybrid Differential evolution with biogeographybased optimization for solution of economic load dispatch. IEEE Trans. Power Syst., 25: 1955-1964. DOI: 10.1109/TPWRS.2010.2043270

Chen, P.H. and H.C. Chang, 1995. Large-scale economic dispatch by genetic algorithm. IEEE Trans. Power Syst., 10: 1919-1926. DOI: $10.1109 / 59.476058$
Das, S., A. Abraham and A. Konar, 2008. Particle Swarm Optimization and Differential Evolution Algorithms: Technical Analysis, Applications and Hybridization Perspectives. 1st Edn., SpringerVerlag Berlin Heidelberg.

Gaing, Z.L., 2003. Particle Swarm optimization to solving the economic dispatch considering the generator constraints. IEEE Trans. Power Syst., 18: 1187-1195. DOI: 10.1109/TPWRS.2003.814889

Khamsawang, S. and S. Jiriwibhakorn, 2009. Solving the economic dispatch problem using novel particle swarm optimization. Int. J. Elec., Comput. Syst. Eng., 3: 41-46.

Khamsawang, S., P. Wannakarn, S. Pothiya and S. Jiriwibhakorn, 2009. Solving the economic dispatch problem by using differential evolution. Proceedings of the 6th International Conference on Electrical Engineering/Electronics, Computer, Telecommunications and Information Technology, May 6-9, IEEE Xplore Press, Chonburi, Thailand, pp: 212-215. DOI: 10.1109/ECTICON.2009.5136995

Kuo, C.C., 2008. A novel coding scheme for practical economic dispatch by modified particle swarm approach. IEEE Trans. Power Syst., 23: 18251835. DOI: 10.1109/TPWRS.2008.2002297

Orero, S.O. and M.R. Irving, 1996. Economic dispatch of generators with prohibited operating zones: A genetic algorithm approach. IEE Proce. Gener. Trans. Distrib., 143: 529-534. DOI: 10.1049/ipgtd:19960626

Selvakumar, I.A. and K. Thanushkodi, 2007. A new particle swarm optimization solution to nonconvex economic dispatch problems. IEEE Trans. Power Syst., 22: 42-51. 10.1109/TPWRS.2006.889132

Su, C.T. and C.T. Lin, 2000. New approach with a Hopfield modeling framework to economic dispatch. IEEE Trans. Power Syst., 15: 541-545. DOI: $10.1109 / 59.867138$

Wong, K.P. and C.C. Fung, 1993. Simulated annealing based economic dispatch algorithm. IEE Proce. Gen. Trans. and Distrib., 140: 509-515.

Wong, K.P., 1995. Solving power system optimization problems using simulated annealing. Engin. Appli. Artificial Intel., 8: 665-670. DOI: 10.1016/09521976(95)00042-9

Wood, A.J. and B.F. Wollenberg, 1996. Power Generation, Operation and Control. 2nd Edn., John Wiley and Sons, New York, ISBN-10: 0471586994, pp: 592. 